\title{
Influence of antioxidant vitamins supplementation on blood glucose levels and body wastages of alloxan-induced diabetic rats
}

\author{
M. K. DALLATU ${ }^{1 *}$, P. O. ANAJA ${ }^{2}$, L. S. Bilbis ${ }^{3}$, F. B. O. MOJIMINIYI ${ }^{4}$, \\ A. S. MAINASARA ${ }^{5}$ and Y. Q. RIZVI ${ }^{6}$ \\ ${ }^{I}$ Department of Chemical Pathology, School of Medical Laboratory Sciences, College of Health Sciences, \\ Usmanu Danfodiyo University, Sokoto, Nigeria. \\ ${ }^{2}$ Department of Chemical Pathology, Ahmadu Bello University Teaching Hospital, Zaria, Nigeria. \\ ${ }^{3}$ Department of Biochemistry, Faculty of Science, Usmanu Danfodiyo University, Sokoto, Nigeria. \\ ${ }^{4}$ Department of Physiology, College of Health Sciences, Usmanu Danfodiyo University, Sokoto, Nigeria. \\ ${ }^{5}$ Department of Pathology/Microbiology, College of Health Sciences, Usmanu Danfodiyo University, Sokoto, \\ Nigeria. \\ ${ }^{6}$ Center for Cardiovascular Diseases, College of Pharmacy and Health Sciences, Texas Southern University, \\ Houston, Texas, USA. \\ *Corresponding author, E-mail: mkdl2000@yahoo.com,Tel:+2348065457656
}

\begin{abstract}
There is increasing evidence that in certain pathology states, the increased production and/or ineffective scavenging of reactive oxygen species (ROS) may play a critical role. Therefore, it seems reasonable that antioxidants can play an important role in the management of these diseases. In the current study, antioxidant vitamins $\mathrm{A}, \mathrm{C}$ and $\mathrm{E}$ were supplemented in alloxan-induced diabetic rats for a period of 28 days. Blood glucose level was assayed by the method of Trinder (1969) and digital bench weigh balance was used to measure the weights. Final blood glucose concentrations were $4.16 \pm 0.18 \mathrm{mmo} / \mathrm{L}$ in control, $5.94 \pm 0.21 \mathrm{mmol} / \mathrm{L}$ in diabetic treated not supplemented and $4.56 \pm 0.61 \mathrm{mmol} / \mathrm{L}$ in diabetic rats supplemented with vitamins. There were statistically significance deference, $(\mathrm{P}<0.05)$ between the supplemented and unsupplemented. Finally body weights were $157.57 \pm 4.16 \mathrm{~g}$ in controls, $143.43 \pm 8.70 \mathrm{~g}$ in diabetic not supplemented and $187.29 \pm 4.30$ $\mathrm{g}$ in diabetic rats supplemented with vitamins. There were statistically significance difference between the supplemented and unsupplemented groups $(\mathrm{P}<0.05)$. These findings suggest, in addition to oral hypoglycaemic agents, supplementation with antioxidant vitamins may improve glycaemic control and alleviates body wastage in alloxan-induced diabetic rats.
\end{abstract}

(C) 2011 International Formulae Group. All rights reserved.

Keywords: Diabetes, Vitamins, Blood Glucose, Body Weight.

\section{INTRODUCTION}

Metformin (dimethylbiguanide) is the most widely used drug for the treatment of type 2 diabetes, but its insulin sensitizing action permits the residual insulin secretion in type 1 diabetes with (Kirpichnikov, 2002).
In the process of cellular respiration, part of the oxygen taken into living cells is changed to several harmful reactive oxygen species (ROS) and free radicals (Al Mamun et al., 2007), and if un attenuated, increased ROS production may served as potent oxidants that selectively affect specific oxidant-sensitive 
proteins and other macromolecules in the body (Richard and Xiao Yong, 2010).

Once formed, free radicals can start a chain reaction leading to formation of more free radicals. Superoxide anion radical $\left(\mathrm{O}_{2}{ }^{-}\right)$is one of the strongest reactive oxygen species among the free radicals that are generated first after oxygen is taken into living cells. $\mathrm{O}_{2}{ }^{-}$ changes to other harmful reactive oxygen species and free radicals such as hydrogen peroxide and hydroxyl radicals, which are implicated in the aetiology of many cardiovascular diseases such as diabetes mellitus (Furukawa et al., 2004).

Under physiological conditions, blood glucose level is kept in narrow range despite periods of food intake or fasting. Insulin secretion from pancreatic $\beta$-Cells is the only efficient means to decrease blood glucose concentration. Accordingly, insulin secretion is strictly controlled by glucose, hormones and autonomic nervous system activities (Kumitoshi et al., 2011).

$\beta$-cells are reported to be particularly sensitive to ROS because they are low in freeradical quenching (antioxidant) enzymes such as catalase, glutathione peroxidase and superoxide dismutase (Lei and Vataminiuk, 2011). Therefore, the ability of oxidative stress to damage mitochondria and markedly blunt insulin secretion is not surprising (Robertson et al., 2003). Intracellular ROS increased in minutes after exposure to high glucose and this effect was blunted by inhibitors of mitochondrial function (Sakai et al., 2003). ROS therefore may serves as antagonist to noble actions of Metformin, which suggest that ROS play a significant role in the development and later complications observed in patients with diabetes mellitus. Insult to cell components might partly in addition to nitrogen wastage, be responsible for the body wastages usually experienced in patients with diabetes mellitus.

In an attempt to strengthened the de novo antioxidant defences against these oxidative insult, our laboratory have earlier reported the beneficial effect of supplementation with antioxidant minerals zinc, copper and manganese in similar subjects (Dallatu et al., 2010). Earlier than that, some researchers from our laboratory (Aliyu et al., 2005), have also reported a decreased blood levels of some antioxidant vitamins in patients with diabetes mellitus.

The objective of the current study was to find out the effect of supplementation with antioxidant vitamins $\mathrm{A}, \mathrm{C}$ and $\mathrm{E}$ on blood glucose regulation and body wastage in alloxan-induced diabetic rat models. These we believe, will go along way in our utmost goal of finding a respire to patients with diabetes mellitus.

\section{MATERIALS AND METHODS \\ Experimental animals}

Male albino Wister rats weighing between (120-180 g) were purchased from the Animal House, Faculty of Pharmaceutical Sciences, Ahmadu Bello University, Zaria, Nigeria. The animals were housed for a period of one week under similar conditions in standard cages at $25 \pm 2{ }^{\circ} \mathrm{C}$, with 12-hour light/dark cycle. The animals were maintained on water and standard animal feed (Vital Feeds, Jos) ad libitum.

\section{Chemicals}

All the reagents used for the study were of analytical grade. Alloxan was purchased from Sigma Aldrich Chemical Co. (U.K), kits for the assay of serum glucose was purchase from Randox Laboratories (Country Antrim, UK). The vitamins used in the study (vitamin A, Pure Source Inc. Miami, USA: Vitamin E, Nutricap Labs, Farmingdale, NY. USA: Vitamin C, Emzor Pharmaceutical Industries, Lagos, Nigeria) were purchased from a reputable pharmacy in Zaria Town, Kaduna State-Nigeria.

\section{Induction of diabetes}

Experimental diabetes was induced by a single intraperitonial injection of freshly dissolved alloxan monohydrate $(150 \mathrm{mg} / \mathrm{kg}$ b.w.) in normal saline maintained at $37{ }^{\circ} \mathrm{C}$, to rats fasted for 12 hours. Control rats received a similar volume of normal saline alone. After 
72 hours of alloxan injection, the animals were fasted overnight and their fasting blood glucose were estimated using a glucometer based on glucose oxidase method (Trinder, 1969). Only rats that had fasting blood glucose level of $>126 \mathrm{mg} / \mathrm{dl}$ (> $7.00 \mathrm{mmol} / \mathrm{l})$ set by WHO as diagnostic and partial destruction of pancreas tested with positive response to metformin were included in the study (Okamato, 1985).

\section{Experimental Design}

The animals were divided into 3 groups of 7 rats each:- Group i: control (received normal saline only); Group ii diabetic treated not supplemented (DTNS) received orally, metformin (250 mg/kgbw) only; Group iii: diabetic treated and supplemented with vitamins (DTSV) received orally metformin $(250 \mathrm{mg} / \mathrm{kgbw})+$ vitamin A $(30 \mathrm{mg} / \mathrm{kgbw})+$ vitamin C (100 mg/kgbw) + vitamin E (30 $\mathrm{mg} / \mathrm{kgbw}$ ). The supplementation and treatment was on daily basis and lasted for 28 days. After the last day; the animals were fasted overnight and euthanized by dropping each in a transparent plastic jar saturated with chloroform vapor. Incision was made on the abdomen. Blood sample was collected through cardiac puncture and divided into plain and EDTA-containing centrifuge tubes for biochemical and hematological (not reported) indices respectively. Acceptable procedure was adopted throughout the experiment.

\section{Measurement of biochemical analytes}

Blood glucose concentration was assayed as described by the method of Trinder, 1969. $10 \mu \mathrm{l}$ of serum sample was mixed with $1 \mathrm{ml}$ of glucose oxidase reagent and incubated at $37{ }^{\circ} \mathrm{C}$ for 30 minutes. Absorbencies were taken at $505 \mathrm{~nm}$. A \& D FX-30001digital bench weight balance (World Precision Instruments, Sarasota, FL. USA) was used to measure the weights.

\section{Statistical analysis}

All data were expressed as the mean \pm Standard Error of Mean (S.E.M). Data were analyzed using Analysis of Variance (ANOVA) InStat3 Software. Differences in mean at $\mathrm{p}<0.05$ was considered significant.

\section{RESULTS AND DISCUSSION}

It is accepted that oxidative stress results from an imbalance between the generation of oxygen derived radicals and the organism's antioxidant potential (Abdullahi et al., 2004). Various studies have shown that diabetes mellitus is associated with increased formation of free radicals and decrease in antioxidant weaponry. Due to these events, the balance normally present in cells between radical formation and protection against them is disturbed (Rahimi et al., 2005). It is therefore logical, that agents with antioxidant potentials, may play some role in the management of the diseases. In the current study, blood glucose level of diabetic rats treated with oral hypoglycemic agent metformin was $5.94 \pm 0.21 \mathrm{mmol} / \mathrm{L}$ but following supplementation of the treatment with antioxidant vitamins, the value significantly decreased to $4.56 \pm 0.16 \mathrm{mmol} / \mathrm{L}$ as shown in Figure 1. We are also able to show that the body westage usually experienced in some diabetic subjects, may improved if antioxidant vitamins are co administered in a controlled dosage with routine oral hypoglycemic agents. In these diabetic models, mean body weight of diabetic rats treated with metformin alone was $14.43 \pm$ $8.70 \mathrm{~g}$, but following supplementation with antioxidant vitamins, the body weight significantly improved to $187.29 \pm 4.30 \mathrm{~g}$ as shown in Table 2. Our findings were in agreement with the findings of other researchers elsewhere. Mahesh and Menon (2004) reported a reduction in blood glucose, plasma TBA reactive substances and hydroperoxides in streptozocin-induced diabetic rats supplemented with quercetin, vitamins C and E. Kedziora-kornatowska et al. (2003) however, reported an improved activities of Superoxide dismutase (SOD), Catalase (CAT), Glutathione Peroxidase (GPX) and a decreased concentration of Malandoaldehyde (MDA) with no effect on 
blood glucose, body weight and HbAic level after supplementation with same antioxidant vitamins. Alshamsi et al. (2004) reported that vitamins may play a role in improving metabolic parameters of diabetic rats, as such invariably attenuate body wastages.

ROS are reported to be among the important factors that impair metabolism and secretory action of $\beta$ Cells. Exposure to excessive ROS reduces glucose-induced insulin secretion by impairing mitochondrial metabolism in $\beta$-Cells (Maechler et al., 1999). Bindokas et al. (2003) have reported that an increased endogeneous ROS impairs glucoseinduced insulin secretion from $\beta$-Cells of diabetic zucker rats and that the level of superoxide in there islets cells at basal glucose level is higher than in zucker control rats.

These nutrients directly affect blood glucose homeostasis and, in turn, poor blood glucose control too, can significantly alter the status of the nutrients. The combined scavenging effect of these vitamins might control the rising tendencies of ROS in these animals, allow for better glucose homeostasis and spare the cells from oxidative insults, thereby improving their body weight. These interplay may therefore provide further evidence, that pharmacological intervention with different antioxidant may have significant implications in the prevention of pro oxidation features of diabetes, and may protect cells against oxidative insult (Naziroglu and Butterworth, 2005).

Supplementing routine diabetes treatment regime with agents with antioxidant potentials might be a promising attempt as evidenced in the current communication. We recommend further work in this area to elucidate the mechanistic role played by these nutrients in this state.

Table 1: Mean serum glucose concentration ( $\mathrm{mmol} / \mathrm{L})$ of alloxan induced diabetic rats supplemented with antioxidant vitamins.

\begin{tabular}{lcc}
\hline Group & $\begin{array}{c}\text { F.B.G Concentration } \\
\text { (Day 1) } \\
(\mathbf{m m o l} / \mathbf{L})\end{array}$ & $\begin{array}{c}\text { F.B.G Concentration } \\
\text { (Day 28) } \\
(\mathbf{m m o l} / \mathbf{L})\end{array}$ \\
\hline A (Controls) & $4.29 \pm 0.24$ & $4.16 \pm 0.18$ \\
B (D.T.N.S) & $22.67 \pm 1.14^{*}$ & $5.94 \pm 0.21^{*}$ \\
C (D.T.S.V) & $24.89 \pm 1.11^{*}$ & $4.56 \pm 0.61^{* *}$ \\
\hline Values are Mean \pm Standard Error of Mean of alloxan-induced diabetic rats supplemented with antioxidant vitamins for 28 \\
days. ${ }^{*}$ Values differ significantly from control. ${ }^{* *}$ Values differ significantly from unsupplemented. \\
D.T.N.S: Diabetic treated not supplemented \\
D.T.S.V: Diabetic treated and supplemented with vitamin.
\end{tabular}

Table 2: Initial and Final Body Weight of Alloxan-Induced Diabetic Rats Supplemented with Antioxidant Vitamins

\begin{tabular}{lcc}
\hline Group & $\begin{array}{c}\text { Initial body weight } \\
(\mathbf{g})\end{array}$ & $\begin{array}{c}\text { Final body weight } \\
(\mathbf{g})\end{array}$ \\
\hline A (Controls) & $155.14 \pm 4.25$ & $157.57 \pm 4.16$ \\
B (D.T.N.S) & $147.14 \pm 7.91$ & $143.43 \pm 8.70^{*}$ \\
C (D.T.S.V) & $116.29 \pm 5.59$ & $187.29 \pm 4.30^{* *}$ \\
\hline Values are Mean \pm Standard Error of Mean of alloxan-induced diabetic rats supplemented with antioxidant vitamins for 28 \\
days. "Values differ significantly from control. ${ }^{* *}$ Values differ significantly from unsupplemented. \\
D.T.N.S: Diabetic treated not supplemented \\
D.T.S.V: Diabetic treated and supplemented with vitamin.
\end{tabular}




\section{ACKNOWLEDGEMENTS}

The authors want to recognize the assistance of University Management for awarding the study leave, and to the staff of Faculties of Medicine and Pharmaceutical Sciences, Ahmadu Bello University, Zaria, Nigeria for their cooperation.

\section{REFERENCES}

Abdollahi M, Bahreini-Moghadam A, Emami B, Fooladian F, Zafari K. 2003. Increasing intracellular cAMP and cGMP inhibits cadmium induced oxidative stress in rat submandibular saliva. Comp. Biochem. Physiol., 135: 331-6.

Aliyu M, Lawal M, Mojiminiyi FBO, Saidu Y, Bilbis LS. 2005. Serum antioxidant vitamins levels in non-insulin-dependent diabetes mellitus subjects in sokoto, Nigeria. Biokemistri., 17(2): 107-114.

Alshamsi MS, Amin A, Adeghate E. 2004. Beneficial effect of vitamin $\mathrm{E}$ on the metabolic parameters of diabetic rats. $\mathrm{Mol}$ Cell. Biochem., 261(1-2): 35-42.

Al-Mamun M, Koji M, Toshiki M, Yumi N, Katsumi S, Hiroaki S, Yoshifumi T. 2007. Superoxide anion radical scavenging activities of herbs and pastures in Northern Japan determined using electron spin resonance spectrometry. Int. J. Biol. Sci., 3(6): 349355.

Arnlov J, Zethelius B, Riserus U, Basu S, Berne C, Vessby B, Alfthan G, Helmerson J. 2009. Serum and dietary beta carotene and $\alpha$-tocopherol and incidence of type 2 diabetes mellitus in a community based study of Swedish men. Diabetologia., 52(1): 97-105.

Bindokas VP, Kuznetsov A, Sreenan S, Polonsky KS, Roe MW, Philipson LH. 2003. Visualising superoxide production in normal and diabetic rats islets of langerhans. J. Biol. Chem., 278: 97969801.

Dallatu MK, Anaja PO, Bilbis LS, Mojiminiyi FBO. 2010. Blood glucose and body weight control of experimental diabetic rats co-treated with micronutrients. Nig. J. Biol. Invest., 8(1): 21-24.

Furukawa S, Fujita T, Shimabukuro M, Iwaki M, Yamada Y, Nakajima Y, Nakayama O, Makishima M, Matsuda M, Shimomura I. 2004. Increased oxidative stress in obesity and its impact on metabolic syndrome. J. Clin. Invest., 114: 1752-1761.

Gwarzo MY, Nwachuku VA, Lateef AO. 2010. Prevention of alloxan-induced diabetes mellitus in rats by vitamin A dietary supplementation. Asian J. Anim. Sci., 4: 190-196.

Kirpichnikov D, Mc Farlane SI, Sowers JR. 2002. Metformin:an update. Ann. Intern. Med., 137: 25-33.

Kedziora-kornatowska K, Szram S, Kornatowski T, Szadujkes-Szadurski L, Kedziora J, Bartozs G. 2003. Effect of vitamin $\mathrm{A}$ and $\mathrm{C}$ supplementation on antioxidative state and renal glomerular basement membrane thickness in diabetic kidnes. Nephron. Exp.Nephrol., 95(4): 134-143.

Kumitoshi U, Katsuya D, Boldbaata D, Hitoshi I, Tetsuya S, Yasuo M, Toshihiko Y, Yasuhiko M, Makoto T. 2011. Lack of TRPM2 impaired insulin secretion and glucose metabolism in mice. Diabetes., 60: $119-126$.

Lei XG, Vataminiuk MZ. 2010. Two tales of antioxidant enzymes on $\beta$ cells and diabetes. Antiox. Redox. Signal., 14(3) : 489-503.

Maechler P, Jornot L, Wollheim CB. 1999. Hydrogen Peroxide alters mitochondrial activation and insulin secretion in pancreatic beta cells. J. Biol. Chem., 274: 27905-27913.

Mahesh T, Menon VP. 2004. Quercetin alleviates oxidative stress in streptozotocin-induced diabetic rats. Phytother. Res., 18(2): 123-127.

Naziroglu M, Butterworth PJ. 2005. Protective effect of moderate exercise with dietary vitamin $\mathrm{C}$ and $\mathrm{E}$ on blood antioxidant defense mechanism in rat 
with streptozotocin induced diabetes. Can. J. App. Physiol., 30(2): 172-85.

Okamat S. 1985. Molecular basis of experimental diabetes: Degeneration, ontogenesis and regeneration of pancreatic $\beta$-cells of islet of langerhans. Bio Essay., 2: 15-21.

Penckofer S, Schwertz D, Florczak K. 2002. Oxidative stress and cardiovascular disease in Type 2 Diabetes: The role of antioxidants and prooxidants. $J$. Cardiovasc. Nurs., 16(2): 68-85.

Rahimi R, Nikfar S, Larijani B, Abdullah M. 2005. A review on the role of antioxidants in the management of diabetes and its complications. Biomed. Pharmacother., 59: 365-373.

Richard AC, XiaoYong T. 2010. Vascular oxidative stress: the common link in hypertensive and diabetic vascular disease. J. Cardiovasc. Pharmacol., 55(4): 308-316.
Robertson RP, Harmon J, Tran PO, Tanaka Y, Takahashi H. 2003. Glucose toxicity in $\beta$ cell: type 2 diabetes, good radicals gone bad, and the glutathione Connection. Diabetes., 52: 581-587.

Sakai K, Matsumoto K, Nishikawa T, Suefuji M, Nakamaru K, Hirashima Y, Kawashima J, Shirotani T, Ichinose K, Brownlee M, Araki E. 2003. Mitochondrial reactive oxygen species reduce insulin secretion by pancreatic beta-cells. Biochem. Biophys. Res. Commun., 300: 216-222.

Trinder P. 1969. Blood glucose estimation. In Medical Laboratory Manual for Tropical Countries (Vol. 1, $2^{\text {nd }}$ edn). Cheesbrough M. ELBS: Cambridge; 527-545. 